\title{
Perbandingan Jumlah Epoch Dan Steps Per Epoch Pada Convolutional Neural Network Untuk Meningkatkan Akurasi Dalam Klasifikasi Gambar
}

\author{
Enie Yuliani ${ }^{1}$, Afifah Nur Aini ${ }^{2}$, Chan Uswatun Khasanah ${ }^{3}$ \\ 1,2,3 Magister Teknik Informatika Universitas Amikom Yogyakarta Email: \\ lenie.yuliani@students.amikom.ac.id, ${ }^{2}$ afifah.aini@students.amikom.ac.id, \\ ${ }^{3}$ chan8160@students.amikom.ac.id
}

\begin{abstract}
Abstrak
Convolutional Neural Network (CNN) adalah salah satu jenis neural network yang biasa digunakan pada data image. CNN bisa digunakan untuk mendeteksi dan mengenali objek pada sebuah image. Penelitian ini akan melakukan perbandingan jumlah epoch dan steps per epoch dalam melakukan klasifikasi gambar untuk mendapatkan nilai keakuratan yang tinggi. Dataset yang digunakan terdiri dari dua kategori, yaitu anjing dan kucing. Masing-masing kategori terdapat 100 gambar. Gambar yang digunakan berukuran 32 x 32 pixel. Pada tahap pengujian, epoch yang digunakan berjumlah 25 dan 50 serta jumlah steps per epoch 10 dan 20. Kesimpulan yang didapatkan adalah semakin banyak jumlah epoch dan steps per epoch maka semakin tinggi juga tingkat akurasi pelatihan yang didapatkan.
\end{abstract}

Kata Kunci:CNN, Epoch, Steps per epoch, Akurasi

\section{PENDAHULUAN}

Klasifikasi objek pada gambar secara umum menjadi salah satu masalah dalam visi komputer. Komputer harus mampu mengenali objek pada gambar selayaknya kemampuan manusia dalam mengenali objek, seperti mengenali bunga, kucing, kupu-kupu, dan kambing. Bagi manusia, hal ini merupakan pekerjaan yang mudah. Namun berbeda dengan komputer. Komputer harus belajar dalam mengenali objek atau biasa disebut dengan machine learning. Kita harus memberikan banyak data kepada komputer agar komputer dapat mengenali pola pada suatu objek.

Computer vision dengan Convolutional Neural Network (CNN) telah mendapatkan banyak perhatian dalam beberapa tahun terakhir karena sangat cocok untuk memproses data dalam jumlah yang besar dan memberikan kinerja yang luar biasa gambar yang ada pada Imagenet yang memiliki 1000 kelas dan setiap tahunnya "melahirkan" berbagai macam arsitektur jaringan CNN. CNN memiliki kemampuan untuk mendeteksi dan mengenali objek pada sebuah gambar.

CNN merupakan pengembangan dari Multilayer Perceptron (MLP) untuk mengolah data dua dimensi. Multilayer Perceptron sendiri adalah pengembangan dari Artificial Neural Network (ANN) yang ditujukan untuk menutupi kekurangan ANN dengan single layer perceptron dalam menyelesaikan operasi logika yang kompleks. Hal tersebut dimungkinkan dengan menambah hidden layer yang membuat ANN powerful untuk memecahkan operasi logika yang kompleks (universal approximation) dan sering digunakan untuk permasalah-permasalahan klasifikasi, recognition, dan prediksi.

Tujuan dalam penelitian ini adalah menerapkan Convolutional Neural Network untuk meningkatkan nilai akurasi dalam terhadap objek dan gaya gambar. Sejak diadakannya Imagenet Large Scale Visual Recognition Challenge (ILSVRC), perkembangan CNN semakin pesat. ILSVRC adalah suatu kompetisi tahunan yang melombakan klasifikasi basis datamelakukan klasifikasi dengan membandingkan jumlah epoch dan steps per epoch.

\section{LANDASAN TEORI}

a. Machine Learning

Machine learning adalah aplikasi dari disiplin ilmu kecerdasan buatan (artificial intelligence) yang menggunakan teknik statistika untuk menghasilkan suatu model otomatis dari sekumpulan data dengan tujuan memberikan komputer kemampuan untuk "belajar". Pembelajaran mesin atau machine 
learning memungkinkan komputer mempelajari sejumlah data (learn from data) sehingga dapat menghasilkan suatu model untuk melakukan proses input-output tanpa menggunakan kode program yang dibuat secara eksplisit. Proses belajar tersebut menggunakan algoritma khusus yang disebut machine learning algorithms.

\section{b. Deep Learning}

Deep learning merupakan sub bagian dari machine learning. Machine learning adalah sebuah program komputer yang dapat belajar dari pengalaman dan semakin banyak pengalaman yang diberikan kepada program tersebut maka performa akan semakin baik. Akan tetapi, algoritma machine learning tradisional tidak akan membaik secara signifikan ketika sudah sampai titik tertentu, sebanyak apapun data yang diberikan. Dengan adanya deep learning maka masalah performa dapat teratasi.

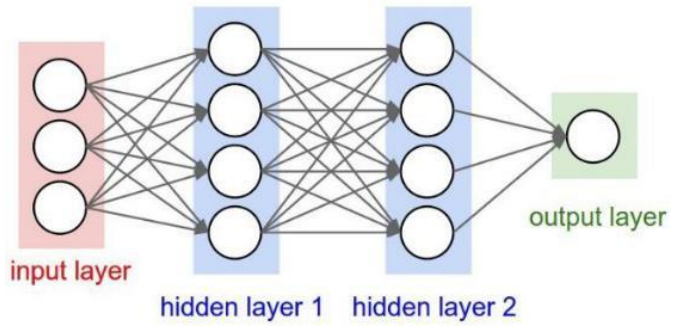

Gambar 1. Deep learning

Secara garis besar, komponen dari algoritma deep learning adalah jaringan syaraf tiruan, sebuah teknik untuk meniru cara berpikir otak manusia yang terdiri dari layer yang berlapis-lapis. Gambar 2 menunjukkan terdapat 4 sel pada hidden layer 1. Lapisan tersebut mendapatkan informasi dari layer input. Bukan hanya satu sel saja yang menjadi masukan, akan tetapi semua sel di layer input. Dengan demikian, hidden layer 1 menjadi tahu kombinasi dari masukan yang menurutnya berpengaruh besar pada hasil. Begitu pun hidden layer 2 akan mendapat masukan dari lapisan sebelumnya, yaitu hidden layer 1 sehingga hidden layer 2 menjadi tahu kombinasi hidden layer 1 seperti apakah yang berpengaruh kepada hasil.

\section{c. Convolutional Neural Network}

Convolutional Neural Network (CNN) merupakan salah satu arsitektur dari deep learning yang dapat menemukan pola spatial dengan baik. CNN dapat digunakan untuk mendeteksi dan mengenali objek pada sebuah image. Arsitektur CNN terdiri dari 2 bagian, yaitu feature extraction layer dan fully connected layer. Feature extraction layer terdiri dari convolutional layer dan pooling layer. Pada fully connected layer inilah proses deep learning dilakukan.

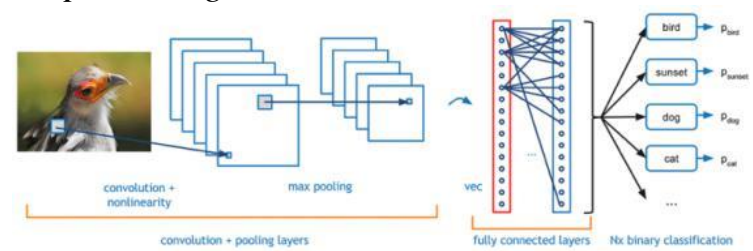

Gambar 2. Proses CNN

\section{HASIL DAN PEMBAHASAN}

\section{a. Perancangan Sistem}

1) Menyiapkan Dataset

Dalam melaksanakan penelitian, langkah pertama yang dilakukan adalah menyiapkan dataset yang akan digunakan dalam proses training. Dataset terdiri dari 2 kategori, yaitu anjing dan kucing. Setiap kategori terdiri dari 100 gambar.

2) Pelatihan Dataset

Pada tahap ini dataset yang telah siap akan dilatih menggunakan Convolutional Neural Network. Proses training ini bertujuan untuk mendapatkan nilai akurasi yang tinggi.

\section{b. Pengujian}

\section{1) Pengujian Jumlah Epoch dan Steps Per Epoch}

Pengujian dilakukan untuk melihat pengaruh dari jumlah epoch dan steps per epoch terhadap tingkat akurasi pada proses training. Pengujian ini melakukan perbandingan antara penggunaan epoch yang berjumlah 25 dan 50 dengan jumlah steps per epoch 10 dan 20.

acc

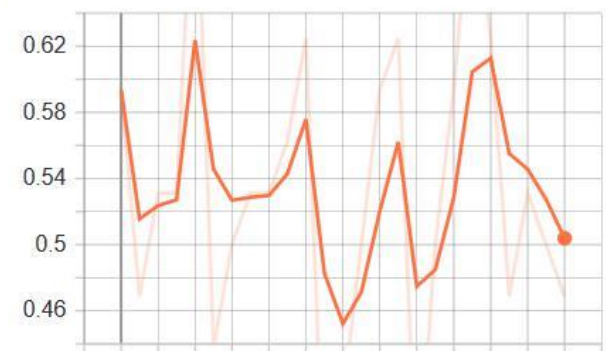

Gambar 3a. Training accuracy sistem epoch 25

loss

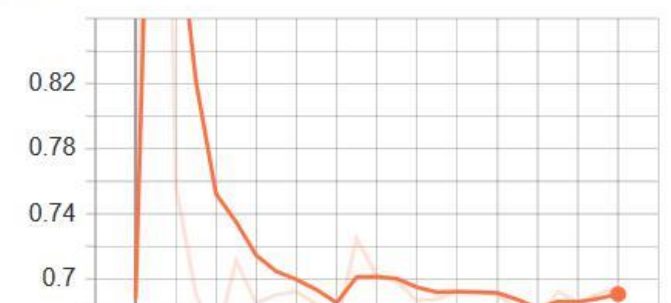


Gambar 3b. Training loss sistem epoh 25

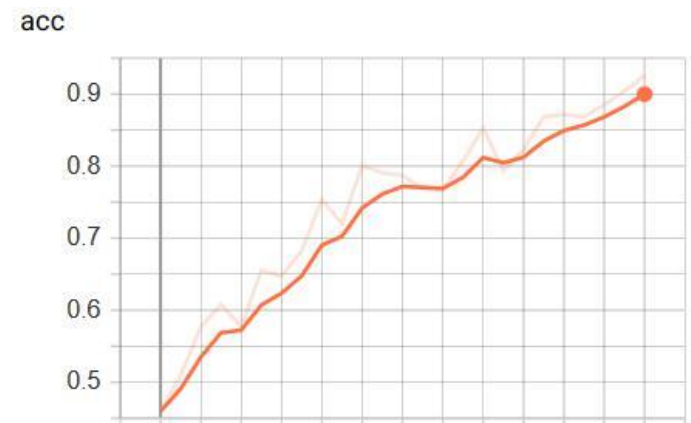

Gambar 4a. Training accuracy sistem epoch 25 dan steps per epoch 10

loss

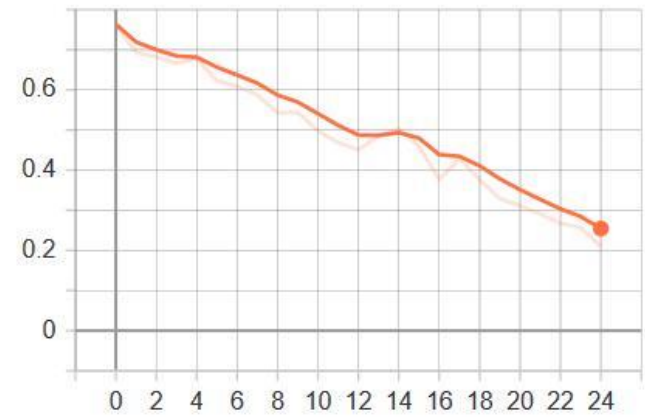

Gambar 4b. Training loss sistem epoch 25 dan steps per epoch 10

Berdasarkan gambar 2a dan 2b, dapat diketahui bahwa dengan menggunakan epoch 25 dan steps per epoch 10 maka menghasilkan tingkat akurasi 93,07\%. acc

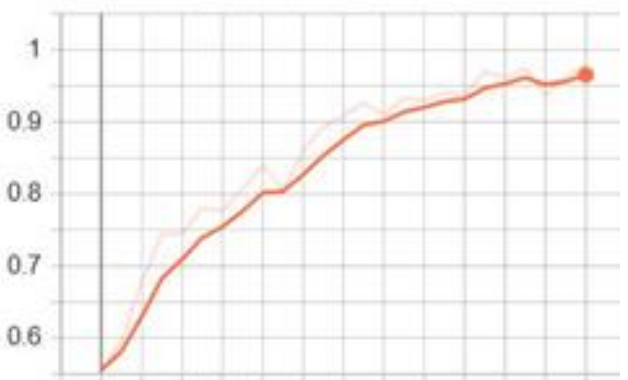

Gambar 5a. Training accuracy sistem epoch 25 dan steps per epoch 20

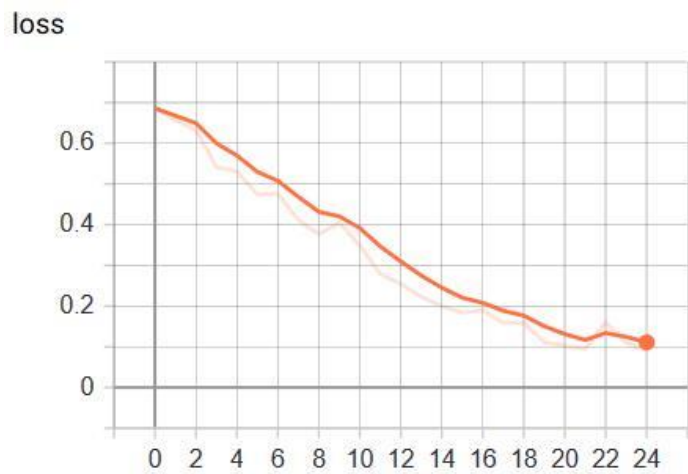

Gambar 5b. Training loss sistem epoch 25 dan steps per epoch 20

Berdasarkan gambar 3a dan 3b, dapat diketahui bahwa dengan menggunakan epoch 25 dan steps per epoch 20 maka menghasilkan tingkat akurasi $98,11 \%$.

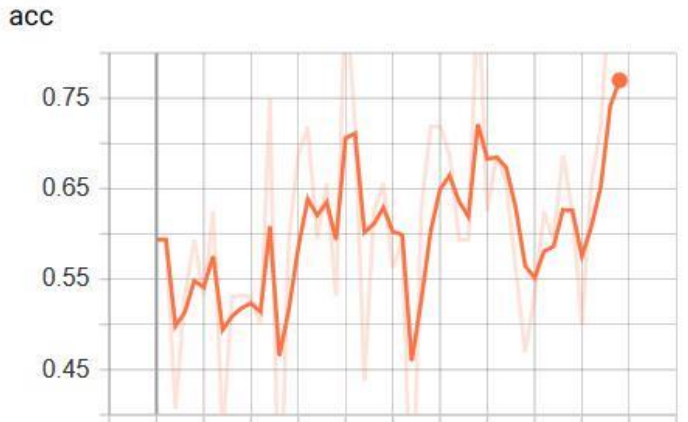

Gambar 6a. Training accuracy sistem epoch 50 


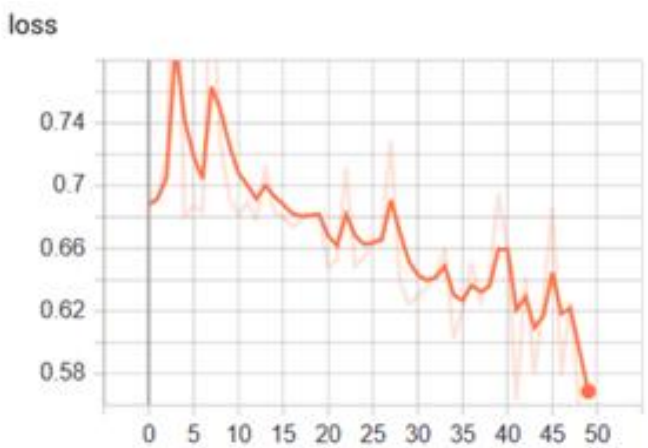

Gambar 6b. Training loss sistem epoch 50

Berdasarkan gambar 4a dan 4b, dapat diketahui bahwa dengan menggunakan epoch 50 dan tanpa menggunakan steps per epoch maka menghasilkan tingkat akurasi $81,25 \%$.

acc

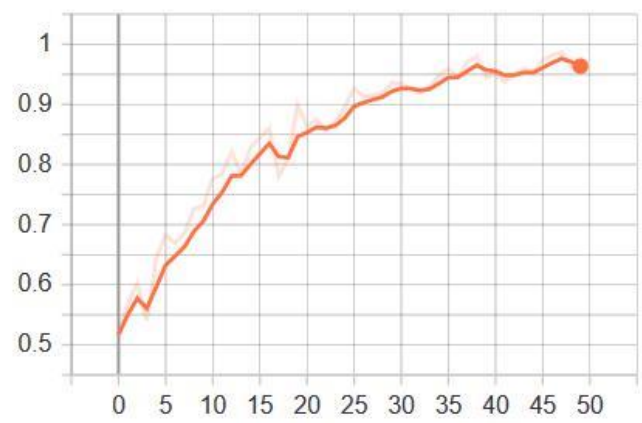

Gambar 7a. Training accuracy sistem epoch 50 dan steps per epoch 10

loss

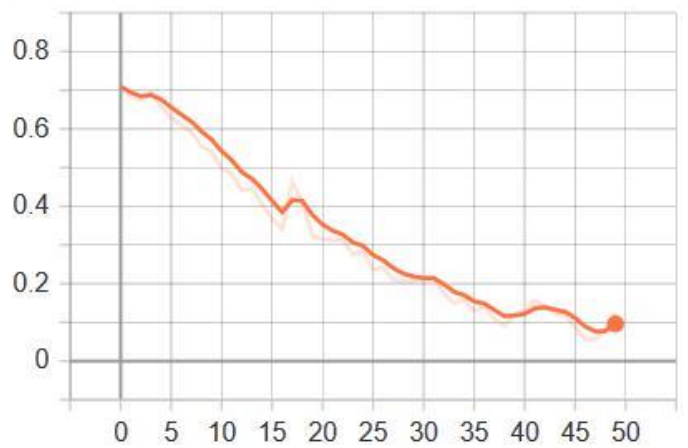

Gambar 7b. Training loss sistem epoch 50 dan steps per epoch 10

Berdasarkan gambar 5a dan 5b, dapat diketahui bahwa dengan menggunakan epoch 50 dan steps per epoch 10 maka menghasilkan tingkat akurasi $99,059 \%$.

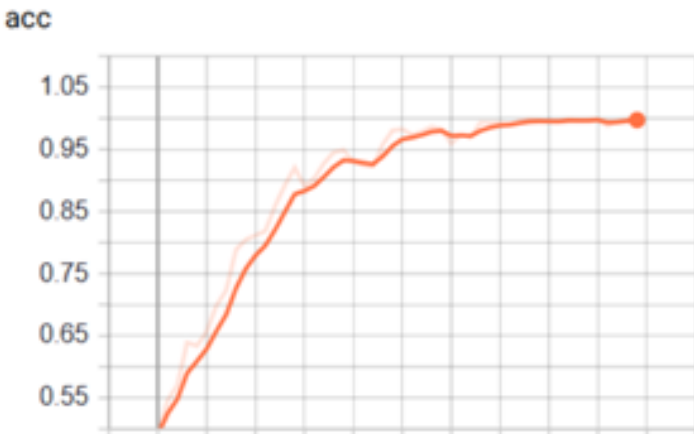

Gambar 8a. Training accuracy sistem epoch 50 dan steps per epoch 20

loss

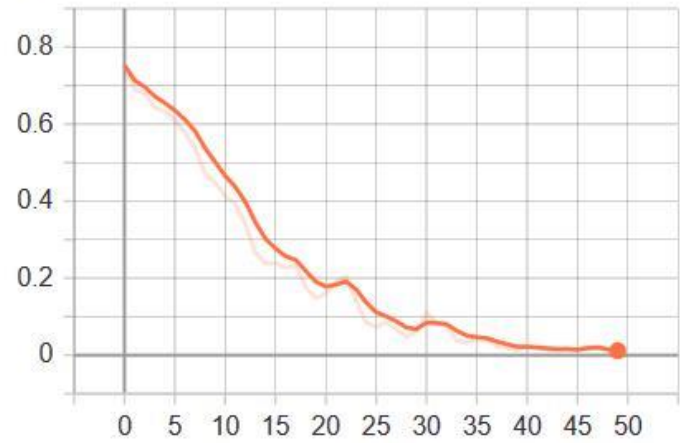

Gambar 8b. Training loss sistem epoch 50 dan steps per epoch 20

Berdasarkan gambar 6a dan 6b, dapat diketahui bahwa dengan menggunakan epoch 50 dan steps per epoch 20 maka menghasilkan tingkat akurasi $100 \%$.

Selain itu juga, dari gambar 1 dan 4 dapat diketahui bahwa dengan epoch yang rendah tanpa menggunakan steps per epoch maka akan menghasilkan nilai akurasi yang rendah. Namun jika tanpa menggunakan steps per epoch tapi dengan jumlah epoch yang banyak maka akan menghasilkan nilai akurasi yang cukup baik 
2) Hasil Pengujian dan Analisis

Pengujian dilakukan menggunakan 25 dan 50 epoch sedangkan steps per epoch yang digunakan adalah 10 dan 20.

Tabel 1. Hasil Pengujian

\begin{tabular}{|c|c|c|c|c|}
\hline $\begin{array}{c}\text { Jumlah } \\
\text { gambar }\end{array}$ & $\begin{array}{c}\text { Image } \\
\text { Size }\end{array}$ & Epoch & $\begin{array}{c}\text { Steps } \\
\text { per } \\
\text { Epoch }\end{array}$ & $\begin{array}{c}\text { Accura } \\
\text { cy } \\
(\%)\end{array}$ \\
\hline \multirow{4}{*}{200} & \multirow{3}{*}{$32 \times 32$} & 25 & - & 46,88 \\
\cline { 3 - 5 } & & 25 & 10 & 93,07 \\
\cline { 3 - 5 } & & 25 & 20 & 98,11 \\
\cline { 3 - 5 } & & 50 & - & 81,25 \\
\cline { 3 - 5 } & & 50 & 10 & 95,59 \\
\cline { 3 - 5 } & 50 & 20 & 100 \\
\hline
\end{tabular}

Berdasarkan tabel hasil pengujian, dapat diketahui bahwa dataset yang berjumlah 200 gambar dengan ukuran $32 \times 32$ pixel menggunakan epoch 25 dan tanpa steps per epoch pada saat proses training menghasilkan tingkat akurasi $46,88 \%$, menggunakan steps per epoch menghasilkan akurasi 93,07\% sedangkan dengan steps per epoch 20 menghasilkan akurasi 98,11\%. Pengujia dengan epoch 50 dan tanpa menggunakan steps per epoch menghasilkan tingkat akurasi $81,25 \%$, menggunakan steps per epoch 10 menghasilkan tingkat akurasi 95,59\%, sedangkan dengan steps per epoch 20 menghasilkan tingkat akurasi $100 \%$. Dari perbandingan tersebut dapat diketahui bahwa jumlah epoch dan steps per epoch berpengaruh terhadap tingkat akurasi. Semakin banyak jumlah epoch dan steps per epoch yang digunakan maka semakin tinggi tingkat akurasi yang didapatkan. Selain itu juga, penggunaan steps per epoch juga dapat meningkatkanakurasi yang didapatkan pada saat proses training.

\section{KESIMPULAN}

Penelitian ini berhasil mengimplementasikan deep learning dengan menggunakan metode Convolutional Neural Network dengan library Tensorflow menghasilkan tingkat akurasi pelatihan (training) yang baik, yaitu $100 \%$. Proses training yang dilakukan menggunakan perbandingan antara jumlah epoch dan steps per epoch. Kesimpulan yang didapatkan adalah semakin banyak jumlah epoch dan steps per epoch maka semakin tinggi juga tingkat akurasi pelatihan yang didapatkan. 